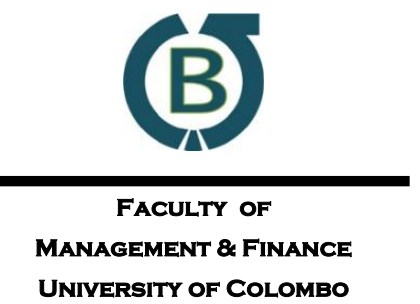

Colombo

Business

Journal

UNIVERSITY OF COLOMBO

INTERNATIONAL JOURNAL OF

THEORY \& PRACTICE

Vol. 10, No. 01, June, 2019

\title{
Convergence in Electricity Consumption among Selected West
}

\section{African Countries}

\author{
Yusuf Abdulwahab Hassan $^{a} \bowtie$, Muideen Adejare Isiaka $^{\mathrm{b}}$ \\ ${ }^{a}$ Department of Economics and Development Studies, Federal University of Kashere, \\ Nigeria \\ ${ }^{b}$ Department of Economics, Accounting and Finance, Bells University of Technology,
}

Nigeria

\begin{abstract}
This study tests the convergence in electricity consumption per capita among selected West African countries participating in the integration of their electricity market under the West African Power Pool (WAPP) initiative over the time period of 1971-2014. This study is significant as it helps clarify a concern within the area of energy economics; that is, whether cross-sectional differences in electricity-related measures across countries shrink over time. An answer to this would further help understand how electricity intensity tends to increase in countries that have relatively low electricity intensity for their low-income level. To this end, the study applies panel unit root tests. The results indicate that the per capita electricity consumption is not converging for the selected countries. The findings suggest that the goals of the WAPP initiative have not improved electrification access. Therefore, policymakers need to reassess the programme in order to ensure that its objectives are achieved.
\end{abstract}

Keywords: Convergence, Electricity Consumption, Panel Unit Root Test, WAPP

$\begin{array}{lll}\text { Received: } & \text { Accepted revised version: } & \text { Published: } \\ \text { 16 October 2018 } & \text { 13 February 2019 } & \text { 30 June 2019 }\end{array}$

Suggested citation: Hassan, Y. A. \& Isiaka, M. A (2019). Convergence in electricity consumption among selected West African countries. Colombo Business Journal, (10)1, $1-18$.

DOI: http://doi.org/10.4038/cbj.v10i1.41

(C) 2019 The Authors. This work is licenced under a Creative Commons Attribution 4.0 International Licence which permits unrestricted use, distribution, and reproduction in any medium, provided the original work is properly cited.

凶yabdulwahab@fukashere.edu.ng (iD) https://orcid.org/0000-0003-0219-4622 


\section{Introduction}

During the last decade there has been a surge in the energy literature focusing on understanding whether cross-sectional differences in energy-related measures shrink over time (Borozan, 2017; de Menezes \& Houllier, 2016; D. Kim \& Jeong, 2016; Le, Chang, \& Park, 2017). For this purpose, the energy literature makes use of electricity consumption per capita as a key indicator, highlighting the differences in the level of electricity consumption across countries. At the same time electricity consumption per capita is as tractable as economic welfare or development, and it serves an important role in the development and evaluation of energy efficiency polices. As such, electricity consumption has become one of the top priorities in most countries. Further to that, International Energy Agency (IEA 2018) posit that "global electricity demand doubled between 1990 and 2016 outpacing other fuels". It is therefore important to improve the understanding of how electricity consumption per capita helps to elucidate the link between growth and electricity usage.

In this branch of literature, testing for the null hypothesis of a unit root in energy variables has become a popular strand of research in energy economics. For instance, Narayan and Liu (2015), point out that the energy unit root literature has progressed from using simple univariate unit root test to using structural break unit root test to panel data unit root test both with, and without, structural breaks. Prior to the recent wave of electricity reform that picked up lately in the West African Region, the Nigerian Electric Power Authority (NEPA) was dominant in Nigeria. The Volta River Authority was dominant in Ghana, as was the 'Compagnie d'Energie Electrique du Togo' (CEET) in Togo, 'Société Nationale d'Electricité du Sénégal (SENELEC)' in Senegal. The electricity industry has been widely described as a natural monopoly in which private participation and competition may be unnecessary and even potentially inefficient. Although, the goal of countries participating in the West African Power Pool (WAPP) initiative is to integrate their national power systems into a unified regional electricity market with the goal of providing regular reliable energy at a competitive cost to the citizenry of the Economic Community of West African Countries (ECOWAS) region in the medium and long term. In addition, it also has as its mission to promote and develop power generation and transmission infrastructures as well as to coordinate power exchange among the ECOWAS member states. An objective of energy market integration is centered on more equitable access to energy. Therefore, it is important to understand whether integration of the electricity market unleashes forces of convergence. 
The specific aim of this paper is to test for conditional convergence by employing panel unit root testing. This approach has advantages over conditional test for convergence based on so-called $\beta$ convergence, given that Solow (1956) suggested conditional, and not absolute convergence. Therefore, finding evidence of convergence in electricity consumption per capita would be consistent with the objectives of electricity market integration, namely, promoting not only more efficient but also more equitable access to member countries.

The convergence test may also provide additional insights into the impact of electricity consumption within the stages of economic growth. Further to that, the panel unit root test can trace out the effects of innovations. The impacts of innovation are likely to be permanent for most of the regions, and their electricity consumption behaviours are likely to be path dependent. Particularly the examination of the electricity consumption nexus with respect to WAPP is still a void in the literature. Following this line of research, this paper aims to contribute to the literature on convergence in electricity consumption for a region where more understanding is needed on the link between per capita electricity consumption and growth. The implications of convergence is that, if there is evidence of rapid convergence and growth rates are relatively modest, this suggests that targets to contain growth rates in energy consumption are feasible. Reductions in disparities in energy consumption per capita between countries would imply that such policies have been effective. However, the problem is that quite a lot is known about convergence in aggregate energy consumption per capita for developed countries but quite little is known about the convergence in disaggregated energy variables for developing countries. Specifically, there are only a few studies that have focused on understanding convergence in electricity consumption per capita. Therefore, this study attempts to fill this void by focusing on selected member countries in the Economic Community of West African Countries (ECOWAS), which have come together to integrate the electricity market in the region.

The rest of the paper is structured as follows: The next contains a review of theoretical and empirical literature. It also includes the theoretical framework. This is followed by a description of the data and an outline of the methodology of the analysis. In the next section econometric results are presented and interpreted and the final section contains the conclusion and policy implications.

\section{Literature Review and Theoretical Framework}

\section{Review of Theoretical Literature}

Beginning with a key implication of the Solow framework premised on the negative relationship between the growth rate of output per capita and 
the initial capital-labour ratio, a plethora of studies have tested for the existence or otherwise of convergence (Apergis \& Payne, 2013; Le et al., 2017; Mishra \& Smyth, 2014). Convergence is an interesting but rather imprecise concept, with many interpretations. Convergence concept implies growth convergence in the long-run rather than level convergence and holds regardless of the assumption about stationarity. Convergence is generally defined as the tendency of the often-large gap in living standards across countries to decrease over time (Maza \& Villaverde, 2008).

The phrase conditional convergence was coined by Barro and Sala-i-Martin (1992) as a result of the findings of empirical research that examined the correlation between initial levels of output per capita and its subsequent growth. Controlling for variables that affect steady states, the study found a negative correlation, consistent with the key implication of Solow's model (Helpman, 2004). Barro and Sala-iMartin (1992) findings are consistent with the evidence that there exists convergence within the group of rich countries, but not across the groups of rich and poor countries. Unlike the conclusions from their study, Helpman (2004) points out that lack of convergence suggests that capital accumulation is not the dominant force because it is hypothesised that capital is more productive in capital-scarce countries, which are poor, thereby providing an incentive for faster capital accumulation in the developing part of the world. As a result, their income per capita should have played a major role in shaping patterns of growth. Similarly, a number of studies have shown that as shifting availabilities of energy resources and development of technologies change, shifts to electricity which is considered to be one of the dominant components of secondary energy, have contributed to the marked improvement in energy efficiency. At the same time, the heart of sustainable development goals is the focus on electricity for all. This is connected to the fact that the electricity sector is becoming a critical actor in the global energy system with implications for all fuels including renewable, natural gas coal and nuclear, as well as most technologies. In addition to that, the role of electricity in the economy is an important subject in energy economics, with multiple policy implications. The potential role of electricity in our economies and societies is growing rapidly, and at the same time, electricity as a productive input in the economy is fast becoming an important subject in energy economics, with multiple policy implications. The power sector again is becoming a critical factor in the global energy system with implications for all fuels including renewables, natural gas, coal and nuclear. In a recent report, IEA (2018) observes that the electricity sector now attracts more investment than oil and gas combined. The literature has adopted electricity consumption per capita and energy intensity as key variables to improve the understanding of the concept of convergence in energy 
consumption. Recently Kim (2015) suggested that the world electricity intensity exhibits a long-run upward trend, which points to the claim that electricity consumption has been growing more rapidly than aggregate economic activity. In the case of OECD countries, electricity intensity does not display the same trend as it peaked around the mid-1980s (Westerlund, Thuraisamy, \& Sharma, 2015). This inverted "U" shaped pattern may be due to the fact that, in developed countries, economic structure shifts from manufacturing to services.

Per capita electricity consumption, an energy-related measure, illuminates the links between energy use and human activity. In addition, per capita electricity consumption has been employed as a proxy for economic welfare or development due to the high degree of association between primary energy consumption and welfare across the literature (Kim, 2015). Mozumder and Marathe (2007) demonstrate a strong positive relationship between energy consumption and income relative to the threshold. As the income of the consumer grows beyond a threshold, total energy usage increases at a faster rate than the increase in total consumption. Arto, CapellánPérez, Lago, Bueno, and Bermejo (2016) noted that many studies have demonstrated evidence of strong correlations between energy consumption and living standards. The authors specifically show a coefficient of determination of 0.81 between per capita total primary energy demand and the human development index (HDI).

Anoruo and DiPietro (2014) noted that the alternative to per capita energy consumption as a measure of country welfare is per capita GDP. The authors favour the use of per capita energy consumption when the focus of the study is energy.

Similarly, another group of study has examined conditional convergence in other variables using unit root test (de Menezes \& Houllier, 2016). Testing for convergence has implications for differing conditions for growth in developing countries. In addition, knowing whether consumption or production of energy has a unit root is important in modeling energy, economic growth and other variables within a unit root, cointegration and Granger causality framework (Smyth, 2013).

According to Todaro and Smith (2011) there are two basic reasons why we should expect convergence in income between developed and developing countries. These are due to technological transfers and factor accumulation. The argument for technological transfer is premised on the fact that, with technology transfer, "developing countries do not need to re-invent the wheel" (Todaro \& Smith, 2011). From this theoretical consideration, technology transfer can enable developing 
countries to prematurely transition to very productive techniques of production. Secondly, if income per capita were driven by capital accumulation and a common rate of technological progress only, then growth rates between the poor and the rich countries would have converged. This is because capital is more productive in capitalscarce countries, which are poor, thereby providing an incentive for faster capital accumulation (Helpman, 2004). Testing for conditional convergence is important because it has implications for sustainable energy consumption and this further enhances the understanding of various issues, such as efforts to curtail carbon dioxide emissions, integration of energy access across countries (Mishra \& Smyth, 2014). The importance of improving the understanding of the convergence of per capita electricity consumption is also related in the fact that long-run dynamics of electricity prices are expected to reflect fuel price developments because fossil fuels generally account for a large share in the cost of generation (de Menezes \& Houllier, 2016).

\section{Review of Empirical Literature}

Beginning with the recent wave of using state of the art econometric approaches in energy literature, most papers that focused on convergence have examined convergence of energy consumption per capita or energy intensity using different methods (Csereklyei, Rubio-Varas, \& Stern, 2016; Meng, Payne, \& Lee, 2013; Mishra \& Smyth, 2014; Mulder \& de Groot, 2012). Overall, the results have been mixed. On the other hand, the dynamic aspects of electricity consumption have received relatively less attention. By examining the evolution of electricity consumption, a number of studies have found the possibility of convergence among a set of countries that have relatively similar characteristics (Csereklyei et al., 2016; Mishra \& Smyth, 2014). Recently Kim (2015) examined the dynamic behaviour of aggregate electricity consumption with special emphasis on their convergence patterns while employing the $\log t$ convergence test and multiple component models for 109 countries. The results of the study suggest that relative convergence holds for electricity intensity but not for per capita electricity consumption and that per capita electricity consumption can be better explained by a multi-component model rather than a single component model. The empirical evidence suggests that an important source of per capita electricity consumption divergence may be due to lack of overall convergence in per capita income. Conventional cross-sectional studies have equally employed the notion of convergence, which refers to the negative correlation between initial values and growth rates. Again, it is well known that convergence is a necessity, however, not a sufficient condition for sigmaconvergence defined as the decline in the dispersion of a distribution over time. Similarly, club convergence technique has been employed to investigate whether 
countries' electricity consumption converges over time in the literature. As an example, Herrerias and Liu (2013) employed the club convergence approach to investigate the stochastic electricity intensity convergence across Chinese provinces. The results from the battery of unit root test employed suggest that the majority of the Chinese regions have converged. More recently de Menezes and Houllier (2016) argued that as an integrated market for electricity develops wholesale electricity prices should converge as a result of coupling and increased interconnectivity.

Using a panel KPSS and RALS-LM unit root test with structural break tests for 26 low income, lower middle income and upper-middle income African countries, Pan and Maslyuk-Escobedo (2019) provide evidence that suggest conditional convergence, although the study finds divergence in four countries. Additionally, the study also investigates the catch-up rate between energy consumption levels of African economies and that of China and finds that the catch-up rates stochastically converge to the level of China for nearly half of the African countries in the panel.

In a related study, Borozan (2017) employed the panel unit-root test with and without structural breaks to investigate whether there is evidence of convergence hypothesis in the Croatian region with a focus on per capita electricity consumption. The result of the study suggests that convergence depends primarily on the consumption sector considered and the test applied. At the same time, a series of studies have examined conditional convergence in other variables using unit roots testing approach, including carbon dioxide emissions (Acar, Söderholm, \& Brännlund, 2017; Cheong, Li, \& Shi, 2018). For instance, Acar et al. (2017) extend the empirical literature on testing whether per capita carbon dioxide emissions tend to converge over time and across countries by conducting a meta-analysis. The results display evidence of either divergence or persistent gaps at the global level, and a convergence of per capita carbon dioxide emissions between rich industrialised countries. Recently, Narayan and Liu (2015) employed a GARCH based unit root test that is flexible enough to account for trending variables and structural breaks to a range of time series energy variables. The findings from these studies indicate the necessity to conduct analysis and formulate energy policy measures in electricity consumption time series across regions where there are interests in integrating the electricity market. There is however no consensus in the literature on the unit root properties of disaggregated energy variables by energy type. This is important because stationarity of energy variables might vary according to the sector in which they are involved. There are, however, not enough studies yet for a consensus to emerge on this issue. The main motivation for testing for a unit root in electricity 
consumption is to understand whether shocks have a permanent or temporary effect. A shock refers to an event which takes place at a particular point in the series and which is not confined to the point at which it occurs. A shock is known to have a temporary or short-term effect if after a number of periods the series returns to its original performance level. On the other hand, a shock is known to have a persistent or long-term impact if its short-run impact is carried forward to set a new trend in performance. While improving understanding on the relationship between energy and economic growth, Csereklyei et al. (2016) extend the literature by focusing on developing countries. The authors highlight the fact that stylised facts are historical characteristics of the data that models of energy and economic growth should be able to reproduce. Similarly, Ferguson, Wilkinson, and Hill (2000) also found that a rise in the proportion of energy used in the form of electricity is associated with the increase in wealth as electricity appears to be the energy carrier of choice relative to other energy carriers for most advanced economies. Furthermore, energy use per capita has been increasing in the Southern European and South American countries and conversely in Sweden and the US energy use per capita has been essentially flat since the early 1970s (Csereklyei et al., 2016).

Hence, the purpose of this paper is to build on the contribution of Narayan and Liu (2015), to apply unit root tests to examine conditional convergence in electricity consumption per capita in selected West African countries. This is necessary as it may provide more insights into the impact of electricity consumption within the stages of economic growth. Particularly, the examination of the electricity consumption growth nexus with respect to West African countries participating in the electricity integration market is still a void in the literature which should be addressed. To this end, this study attempts to investigate the case for selected West African countries, particularly a group of countries that have come together to integrate their electricity market tagged as WAPP. An understanding of the question would increase the understanding of the existence or otherwise of convergence in electricity consumption among the selected countries as well as the dynamic behaviour of cross-sectional variations.

\section{Theoretical Framework}

Within the context of the economic growth model, income per capita in a particular country converges to a steady-state value. This is referred to as a conditional convergence because it is determinable only after controlling for the determinants of the steady state (Solow, 1956). The main approaches of convergence study is based on the neoclassical growth theories that have gone through the test of $\beta$-convergence and $\sigma$-convergence using a cross-sectional data series (Barro \& 
Sala-i-Martin, 1995; Baumol, 1986). Bernard and Durlauf (1995) use time series data to examine the stochastic convergence process. Recent advances in panel data econometrics allow researchers to use the panel unit root test in convergence studies (Evans \& Karras, 1996; Im, Pesaran, \& Shin, 2003; Levin, Lin, \& James Chu, 2002). Convergence has also been examined within spatial context (Coe \& Helpman, 1995; Lall \& Yilmaz, 2001).

For the purpose of this study, the per capita electricity consumption for a particular country $i$ in year $t$ is defined as $y_{i t}$. On the assumption that each WAPP country operates in a stochastic world of energy consumption, there is a convergence in per capita electricity consumption of each member $i$ if, and only, if a common trend $\bar{y}_{t}$ and finite parameters $\beta_{1}, \beta_{2}, \ldots \beta_{N}$ exist such that:

$$
\lim _{s \rightarrow \infty} E_{t}\left(y_{i, t+s}-\bar{y}_{t+s}\right)=\beta_{i} \text { for } i=1,2, \ldots, \mathrm{N}
$$

where $\mathrm{N}$ is the total member; $\bar{y}_{t}$ is the common trend followed by the countries; $\beta_{i}$ is a constant parameter (Evans \& Karras, 1996; Guetat \& Serranito, 2007).

In line with Koo and Lee (2000), if we assume that $y_{i t}$ can be decomposed into a mean (equilibrium) value $\bar{y}_{i}$ and a deviation component $u_{i t}$, then $y_{i t}$ follow the following process:

$$
y_{i t}=\bar{y}_{i}+u_{i t}
$$

$\bar{y}_{i}$ represents a time-invariant average level of per capita electricity consumption that each WAPP country is moving towards over time. This may be specific to each member country due to peculiar socio-economic characteristics.

We assume that $u_{i t}$ can be divided into a deterministic linear trend $\beta_{i} t$ and a stochastic process $\mu_{i t}$. Thus, $u_{i t}$ is modeled as:

$$
u_{i t}=u_{o i}+\beta_{i} t+\mu_{i t}
$$

where $u_{o i}$ is the initial deviation from equilibrium while $\beta_{i}$ is the deterministic rate of convergence in Equation 1. Consider two countries $n$ and $m$, if $u_{o n}>u_{o m}$ we expect $\beta_{n}<\beta_{m}$.

Combining Equations 2 and 3, we have:

$$
y_{i t}=\bar{y}_{i}+u_{o i}+\beta_{i} t+\mu_{i t}=\alpha_{i}+\beta_{i} t+\mu_{i t}, \text { where } \alpha_{i}=\bar{y}_{i}+u_{o i}
$$


Convergence implies that deviation of each country's relative trend growth in per capita electricity consumption $\mu_{i t}$ must be temporary. The unit root interpretation of Equation 4, is clear if we modeled $\mu_{i t}$ as an Autoregressive process of order $q$ as:

$$
\left[1-\alpha_{1 i} L-\alpha_{1 i} L^{2}-\cdots-\alpha_{q i} L^{q}\right] \mu_{i t}=\varepsilon_{i t} \Rightarrow A_{i}(L) \mu_{i t}=\varepsilon_{i t}
$$

where $L$ is a lag operator while $\varepsilon_{i t}$ is a serially uncorrelated shock to $\mu_{i t}$.

Convergence implies that $A_{i}(L)$ does not have a unit root. This, for example, can be reduced to a standard Augmented Dickey-fuller equation with $(q-1)$ lagged difference of $y_{i t}$ terms.

\section{Data and Method}

\section{Data}

The data for per capita electricity consumption for the selected countries were collected from the World Development Indicators (World Bank, 2018) database. Electric power consumption measures the production of power plants and combined heat and power plants less transmission, distribution, and transformation losses and own use by heat and power plants (WDI, 2018). Descriptive statistics for each country are presented in Table 1.

Table 1: Descriptive Statistics of Electricity Consumption (1971-2014) for WAPP

\begin{tabular}{lcccccc}
\hline Country & Observation & Mean & Median & SD & Min & Max \\
\hline Nigeria & 44 & 88.82 & 87.06 & 33.31 & 28.57 & 156.7 \\
Ghana & 44 & 318.8 & 334.9 & 72.00 & 93.49 & 425.9 \\
Togo & 44 & 93.64 & 93.99 & 23.55 & 55.57 & 152.7 \\
Sengal & 44 & 123.3 & 107.3 & 40.12 & 73.83 & 223.5 \\
Benin & 44 & 48.24 & 39.25 & 26.16 & 10.75 & 100.2 \\
\hline
\end{tabular}

Notes: Sample consisted of annual data for the period 1971-2014. Electricity consumption is expressed as Electric power consumption which measures the production of power plants and combined heat and power plants, less transmission, distribution, and transformation losses and own use by heat and power plants (WDI, 2018)

Table 1 highlights the fact that Ghana, has the highest average electricity consumption followed by Senegal and Togo. Nigeria rank $4^{\text {th }}$ while Benin has the least energy consumption.

To calculate relative electricity consumption, the approach followed in Mishra and Smyth (2014) was used. 
$=\ln \left(\frac{p c e_{i t}}{\text { ape }_{t}}\right)$

where pce is per capita electricity consumption and ape is average per capita electricity consumption.

All the analysis is conducted on this transformed series. The transformed series is used to measure the convergence properties of electricity consumption. If relative electric consumption is stationary, this suggests that electricity consumption across the WAPP counties is converging. The transformation has the advantage that it filters the cross-sectional shocks that affect all the countries in the panel. This implies that any structural breaks identified in the transformed series would be country specific.

In energy economics literature, Squalli (2007) for example, stress the importance of heterogeneity in formulating causality between electricity consumption and economic growth. To this end, we have used a measure of relative electricity consumption per capita to account for heterogeneity in the panel model. For each country the electricity consumption series was transformed to a measure of relative electric power consumption based on recent approaches in the literature (Mishra \& Smyth, 2014).

\section{Unit Root Test}

The test was commenced with an examination of the dynamic behaviour of the cross-sectional variations in the panel. Extensive progress in both theoretical and empirical approaches to panel data allows researchers to address a variety of new economic issues and to account for the richer dynamic behaviour of economic variables. While there are a number of panel unit root tests, this study utilise a battery of unit root test. Specifically, the panel KPSS stationarity test, the Im et al. (2003) test which assumes individual unit root process and the Levin et al. (2002) test which assume common unit root process were employed. The null hypothesis in the KPSS test is that there is panel stationarity (the given time series is stationary for all individuals) or that electricity consumption is converging. In the gretl software, the KPSS test is implemented using the method of (Choi, 2001) ${ }^{1}$. Several studies have noted that for many applications, stationarity is a more natural null. The panel KPSS test has several advantages. It allows for $n$ structural breaks; it allows the number of

\footnotetext{
${ }^{1}$ This is an application of meta-analysis, the statistical technique whereby an overall or composite $p$-value for the test of a given null hypothesis can be computed from the $p$ values of a set of separate tests.
} 
structural breaks to differ between countries and it reports the results for individual countries.

$$
\Delta y_{i t}=\mu_{i t}+\varphi_{i} y_{i, t-1}+\sum_{j=1}^{p_{i}} \gamma_{i j} \Delta y_{i, t-j}+\varepsilon_{i t}
$$

The main motivation for using the KPSS test is that it allows for maximal heterogeneity across the individuals in the panel; the parameters of the model of the deterministic term, the autoregressive coefficient $\varphi$, and the lag order are all specific to the individual, indexed by $i$. Under the model, in Equation 6 above the joint null is $\varphi_{i}=0$ for all $i$, meaning that all the individual time series are non-stationary, and the alternative (simply the negation of the null) is that at least one individual time series is stationary. When a common $\varphi$ is assumed, the null is $\varphi=0$ and the alternative is $\varphi<0$. $H_{o}: \varphi_{i}=0, H_{1}: \varphi_{i}<0$.

$$
\Delta y_{i t}=\mu_{i t}+\varphi y_{i, t-1}+\sum_{j=1}^{p_{i}} \gamma_{i j} \Delta y_{i, t-j}+\varepsilon_{i t}
$$

Equation 7 represents an alternative model that assumes homogeneity (common value of $\varphi$ ) in the dynamics of the autoregressive coefficients for all panel units. The modification in Equation 7 is that the model imposes the assumption that $\varphi_{i}=\varphi^{2}$ for all $i$; that is the individual time series share a common autoregressive root (although they may differ in respect of other statistical properties). The test has the null hypothesis of $\varphi_{i}=\varphi=0$ for all $i$ against the alternative of $H_{1}=\varphi=\varphi_{i}<0$, which presumes that all the series are stationary.

\section{Results and Discussion}

This section provides an overview of the methods and results. The Bai and Perron (2003) structural break test ${ }^{3}$ was applied first as a benchmark for the results from the panel test. Table 2 reports the results for the WAPP countries in the Bai and Perron (2003) test with multiple structural breaks with maximum break set at $8^{4}$.

\footnotetext{
${ }^{2}$ Autoregressive parameters are considered to be identical across the panel in this model.

${ }^{3}$ The package allows (i) test for and (ii) estimate dates of structural breaks, and (iii) estimate other parameters in the presence of such breaks in a single time- series regression.

${ }^{4}$ The test was implemented using http://ricardo.ecn.wfu.edu/gretl/cgi-bin/gretldata.cgi? Opt =SHOW_FUNCS package.
} 
Table 2: Structural Break Tests for Per Capita Electricity Consumption

\begin{tabular}{|c|c|c|c|c|c|}
\hline & Nigeria & Ghana & Togo & Senegal & Benin \\
\hline $\begin{array}{l}\text { Number of breaks } \\
\text { chosen } \\
\text { (BIC) }\end{array}$ & 1 & 0 & 0 & 0 & 1 \\
\hline UDmax & $11.431 *$ & 10.428 & $13.929 * *$ & 9.994 & $56.651 * *$ \\
\hline WDmax & $14.37 * *$ & 10.88 & $16.13^{* *}$ & 11.75 & $65.59 * *$ \\
\hline $\operatorname{SupF}_{\mathrm{T}}(1 \backslash 0)$ & 11.432 & $10.428 *$ & 8.664 & 9.995 & 8.077 \\
\hline $\operatorname{SupF}_{\mathrm{T}}(2 \backslash 0)$ & $11.189 * *$ & 5.44 & 13.929 & 6.047 & $56.652 * *$ \\
\hline $\operatorname{SupF}_{\mathrm{T}}(3 \backslash 0)$ & $10.897 * *$ & 8.254 & $10.427 * *$ & $8.913 *$ & $38.244 *$ \\
\hline $\operatorname{SupF}_{T}(2 \backslash 1)$ & 10.93 & 1.84 & 8.73 & 10.77 & 6.87 \\
\hline $\operatorname{SupF}_{\mathrm{T}}(3 \backslash 2)$ & 10.79 & 12.45 & 1.90 & 16.71 & 7.30 \\
\hline
\end{tabular}

Note: $* *$ and $*$ denote significance levels $p<0.05$ and $p<0.1$, respectively

In the case of Nigeria, testing none against 2 or 3 breaks is significant here at "conventional" levels. Against 1 break it is borderline (10\%, but not 5\%). Both UDmax and WDmax again are borderline, and as it says, against an unspecified (unknown) number of breaks under the alternative hypothesis. $\operatorname{SupF}(1+1 / 1)$ test using global optimisers under the null are not significant. Therefore, taking these results together the evidence is mixed when deciding on evidence of structural break in the individual series. Similarly, in the case of Benin the BIC criteria suggest one structural break in the series, testing no break against 2 or 3 breaks is significant here at the 5\% level. Against 1 break it is also borderline (10\%). Both UDmax and WDmax again are borderline. $\operatorname{SupF}(1+1 / 1)$ test using global optimisers under the null are not significant in all of our sample countries. Therefore, taking these results together it appears that the evidence is mixed.

The analysis then proceeded to the Levin Lin and Chu panel test along with the KPSS tests. The results of these tests provide mixed evidence of convergence (see Table 3).

The hypothesis of convergence (i.e. panel stationarity) is rejected in the panel when the study considers the autoregressive coefficient as homogenous in the KPSS test, while in the second test that specifically utilizes the Levin et al. (2002) test, the study fails to reject the hypothesis that the series have a unit root. Therefore, it seems fairly logical that common causes can influence electricity consumption in different countries making the KPSS test to over reject substantially the null of convergence. The results of this study are similar to Pan and Maslyuk-Escobedo (2019) that points 
to convergence after taking into consideration cross sectional dependence and structural breaks in the data.

Table 3: Results of Panel KPSS and Levin, Lin \& Chu Tests

\begin{tabular}{llll}
\hline $\begin{array}{l}\text { WAPP } \\
\text { Countries }\end{array}$ & $\begin{array}{l}\text { Panel KPSS test } \\
\text { (using Choi test) }\end{array}$ & $\begin{array}{l}\text { Levin, Lin \& Chu test } \\
\text { (using Bartlett } \\
\text { Truncation) }\end{array}$ & $\begin{array}{l}\text { Im, Pesaran \& } \\
\text { Shin (2003) test }\end{array}$ \\
\hline $\begin{array}{l}\text { Breaks } \\
\text { (Heterogenous) }\end{array}$ & $-5.4923(0.0000)$ & & $-1.1716(0.1207)$ \\
$\begin{array}{l}\text { Breaks } \\
\text { (Homogenous) }\end{array}$ & & $-6.232(0.2160)$ & \\
\hline
\end{tabular}

\section{Conclusion}

The possibility of convergence in electricity consumption for a set of countries sharing common characteristics has been documented in a number of empirical and theoretical literature. This paper investigates the stationarity properties with a special emphasis on finding a parsimonious representation of the data that gives a reasonable approximation of the true process, by taking heterogeneous transitional dynamics into account. This study specifically used the panel unit root testing to test for evidence of convergence. This is motivated by a branch of literature proposing that when testing for convergence in a set of countries the null is that there is a panel stationarity or that energy consumption is converging. Evidence of convergence in electricity consumption per capita would be consistent with electricity market integration of the WAPP, promoting not only more efficient but also more equitable access to electricity within the region. While utilising a battery of unit root tests the study fails to find evidence of convergence in electricity consumption per capita for the five countries that were selected among the countries participating in the WAPP initiative. It is important to highlight the fact that the lack of convergence across a panel of countries does not necessarily refute the fact that a subgroup of countries can be dominated by a common component (Kim, 2015). These findings are valid irrespective of whether the null is specified to be stationary or non-stationary (convergence or non-convergence). A possible reason why convergence was not found is that five out of seven countries that are classified under Zone A were selected (WAPP grid covers two geographical zones A and B, Zone A are already connected by interconnections). Similarly, by examining the dynamic behaviour of electricity consumption with special focus on convergence patterns, Kim (2015) finds that relative convergence does not hold across a panel of 109 countries, whereas while 
utilising the clustering algorithm the study finds the presence of club convergence for per capita electricity consumption across the panel of countries. Convergence of per capita energy consumption will imply that the WAPP members' growth policy has mean-reverting characteristics implying a stable and predictable growth pattern. This is necessary for regional economic integration and the elimination of inequalities among countries. With convergence, energy supply would become an insignificant bottleneck for economic growth (Anoruo \& DiPietro, 2014).

To summarise the main finding, this paper has presented that for electricity consumption per capita, all five countries do not converge to a common component. This finding has implications for the global power sector reform that began in the early 1990s in the developed countries. The finding helps in understanding the fact that power sector reforms lag far behind in the developing countries when judged against the spectacular progress that has been recorded in the developed countries. The slowdown is particularly evident in terms of the number of countries establishing regulatory entities or conducting private sector participation in generation or distribution. The findings suggest that the goals of WAPP initiative along with the global power sector reforms have not improved electrification access among member counties.

Further studies can apply the clustering algorithm to test for club convergence in aggregate electricity indicator. This is because the $\log t$ convergence test will reject the null of overall convergence even when only one diverging individual exists in a panel while all other individuals are dominated by a single common trend.

\section{Declaration of Conflicting Interests}

The authors declared no potential conflicts of interest with respect to the research, authorship, and publication of this article.

\section{References}

Acar, S., Söderholm, P., \& Brännlund, R. (2017). Convergence of per capita carbon dioxide emissions: implications and meta-analysis. Climate Policy, 18(4), 512525. doi:10.1080/14693062.2017.1314244

Anoruo, E., \& DiPietro, W. R. (2014). Convergence in per capita energy consumption among African countries: evidence from sequential panel selection method. The International Journal of Energy Economics Policy, 4(4), 568-577.

Apergis, N., \& Payne, J. E. (2013). Another Look at the Electricity ConsumptionGrowth Nexus in South America. Energy Sources, Part B: Economics, Planning, and Policy, 8(2), 171-178. doi:10.1080/15567249.2011.653474 
Arto, I., Capellán-Pérez, I., Lago, R., Bueno, G., \& Bermejo, R. (2016). The energy requirements of a developed world. Energy for Sustainable Development, 33, 113.

Bai, J., \& Perron, P. (2003). Computation and analysis of multiple structural change models. Journal of Applied Econometrics, 18(1), 1-22.

Barro, R. J., \& Sala-i-Martin, X. (1992). Convergence. Journal of Political Economy, 100(2), 223-251.

Barro, R. J., \& Sala-i-Martin, X. (1995). Technological diffusion, convergence, and growth. Retrieved from

Baumol, W. J. (1986). Productivity growth, convergence, and welfare: what the longrun data show. The American Economic Review, 1072-1085.

Bernard, A. B., \& Durlauf, S. N. (1995). Convergence in international output. Journal of applied econometrics, 10(2), 97-108.

Borozan, D. (2017). Testing for convergence in electricity consumption across Croatian regions at the consumer's sectoral level. Energy Policy, 102, 145-153. doi: 10.1016/j.enpol.2016.12.018

Cheong, T. S., Li, V. J., \& Shi, X. (2018). Regional disparity and convergence of electricity consumption in China: A distribution dynamics approach. China Economic Review. doi: 10.1016/j.chieco.2018.02.003

Choi, I. (2001). Unit root tests for panel data. Journal of International Money and Finance, 20(2), 249-272. doi: 10.1016/S0261-5606(00)00048-6

Coe, D. T., \& Helpman, E. (1995). International R \& D spillovers. Journal of European Economic Review, 39(5), 859-887.

Csereklyei, Z., Rubio-Varas, M. d. M., \& Stern, D. I. (2016). Energy and Economic Growth: The Stylized Facts. The Energy Journal, 37(2), 223-225. doi:10.5547/01956574.37.2.zcse

de Menezes, L. M., \& Houllier, M. A. (2016). Reassessing the integration of European electricity markets: A fractional cointegration analysis. Energy Economics, 53, 132-150. doi:10.1016/j.eneco.2014.10.021

Evans, P., \& Karras, G. (1996). Convergence revisited. Journal of Monetary Economics, 37(2), 249-265.

Ferguson, R., Wilkinson, W., \& Hill, R. (2000). Electricity use and economic development. Energy Policy, 28(13), 923-934. doi:10.1016/S03014215(00)00081-1

Guetat, I., \& Serranito, F. (2007). Income convergence within the MENA countries: A panel unit root approach. The Quarterly Review of Economics Finance, 46(5), 685-706.

Helpman, E. (2004). The Mystery of Economic Growth. United States of America: The Belknap Press of Harvard University Press, Cambridge, Massachusetts, and London England. 
Herrerias, M. J., \& Liu, G. (2013). Electricity intensity across Chinese provinces: New evidence on convergence and threshold effects. Energy Economics, 36, 268276. doi: 10.1016/j.eneco.2012.08.026

Im, K. S., Pesaran, M. H., \& Shin, Y. (2003). Testing for unit roots in heterogeneous panels. Journal of Econometrics, 115(1), 53-74. doi:10.1016/S03044076(03)00092-7

International Energy Agency. (2018). The year of electricity at the IEA. Retrieved from https://www.iea.org/newsroom/news/2018/april/the-year-of-electricity-atthe-iea.html

Kim, D., \& Jeong, J. (2016). Electricity restructuring, greenhouse gas emissions efficiency and employment reallocation. Energy Policy, 92, 468-476. doi:10.1016/j.enpol.2016.02.009

Kim, Y. S. (2015). Electricity consumption and economic development: are countries converging to a common trend? Energy Economics, 49, 192-202.

Koo, J., \& Lee, S. (2000). Regional income convergence: Evidence from panel unit root tests. Seoul Journal of Economics, 13(4), 459-469.

Lall, S. V., \& Yilmaz, S. (2001). Regional economic convergence: Do policy instruments make a difference? Journal of The Annals of Regional Science, 35(1), 153-166.

Le, T.-H., Chang, Y., \& Park, D. (2017). Energy demand convergence in APEC: An empirical analysis. Energy Economics, 65, 32-41. doi:10.1016/j.eneco.2017.04.013

Levin, A., Lin, C.-F., \& James Chu, C.-S. (2002). Unit root tests in panel data: asymptotic and finite-sample properties. Journal of Econometrics, 108(1), 1-24. doi:10.1016/S0304-4076(01)00098-7

Maza, A., \& Villaverde, J. (2008). The world per capita electricity consumption distribution: Signs of convergence? Energy Policy, 36(11), 4255-4261. doi:10.1016/j.enpol.2008.07.036

Meng, M., Payne, J. E., \& Lee, J. (2013). Convergence in per capita energy use among OECD countries. Energy Economics, 36, 536-545. doi:10.1016/j.eneco.2012.11.002

Mishra, V., \& Smyth, R. (2014). Convergence in energy consumption per capita among ASEAN countries. Energy Policy, 73, 180-185. doi:10.1016/j.enpol.2014.06.006

Mozumder, P., \& Marathe, A. (2007). Causality relationship between electricity consumption and GDP in Bangladesh. Energy Policy, 35(1), 395-402. doi:10.1016/j.enpol.2005.11.033

Mulder, P., \& de Groot, H. L. F. (2012). Structural change and convergence of energy intensity across OECD countries, 1970-2005. Energy Economics, 34(6), 19101921. doi:10.1016/j.eneco.2012.07.023 
Narayan, P. K., \& Liu, R. (2015). A unit root model for trending time-series energy variables. Energy Economics, 50, 391-402. doi:10.1016/j.eneco.2014.11.021

Pan, L., \& Maslyuk-Escobedo, S. (2019). Stochastic convergence in per capita energy consumption and its catch-up rate: evidence from 26 African countries. Applied Economics 51(24), 2566-2590. doi:10.1080/00036846.2018.1549793

Smyth, R. (2013). Are fluctuations in energy variables permanent or transitory? A survey of the literature on the integration properties of energy consumption and production. Applied Energy, 104, 371-378. doi:10.1016/j.apenergy.2012.10.069

Solow, R. M. (1956). A contribution to the theory of economic growth. The Quarterly Journal of Economics, 70(1), 65-94.

Squalli, J. (2007). Electricity consumption and economic growth: Bounds and causality analyses of OPEC members. Energy Economics, 29(6), 1192-1205. doi:10.1016/j.eneco.2006.10.001

Todaro, M. p., \& Smith, S. C. (2011). Economic Development (11 ${ }^{\text {th }}$ Ed). India: Pearson Education.

Westerlund, J., Thuraisamy, K., \& Sharma, S. (2015). On the use of panel cointegration tests in energy economics. Energy Economics, 50, 359-363. doi:10.1016/j.eneco.2014.08.020

World Bank. (2018). World development indicators. Retrieved from https://databank.worldbank.org/data/source/world-development-indicators 